\title{
Diz manyetik rezonans görüntüleme bulguları ve fizik muayene bulgularının artroskopik bulgular ile karşılaştırılması
}

\author{
Melih Malkoç${ }^{1}$, Özgür Korkmaz ${ }^{2}$, Cem Sever ${ }^{3}$
}

\begin{abstract}
ÖZET:
Diz manyetik rezonans görüntüleme bulguları ve fizik muayene bulgularının artroskopik bulgular ile karşılaştırılması

Amaç: Fizik muayene bulguları ile birlikte manyetik rezonans (MR) görüntüleme sonuçlarının artroskopik cerrahi yapılması kararı üzerine olan etkilerini belirlemek.

Yöntem: Kliniğimizde diz artroskopisi yapılan hastaların ameliyat öncesi fizik muayene bulguları ile MR tetkiki sonuçları referans artroskopi alınarak retrospektif olarak istatistiksel değerlendirilmesi yapıldı.

Bulgular: Çalışmaya katılan hastalrın yaş ortalaması 47,2 (22,73) olarak belirlendi. Çalışmadaki hastaIarın 25'i kadın, 20'si erkek, 27sol dize, 18 sağ dize artroskopik cerrahi yapıldı. Medial menisküs yırtığı olan hastalarda Mc murray testinin duyarlıı̆̆ı \%69,8 medial eklem çizgisi hassasiyetinin duyarlıığı \%97,7 MR görüntüleme yönteminin duyarlılığı \%93 olarak belirlenmiştir. Lateral menisküs yırtığı olan hastalarda Mc murray testinin duyarlıığı \%71,4 lateral eklem çizgisi hassasiyetinin duyarlılığı \%100 MR görüntüleme yönteminin duyarlılığı \%85,7 olarak belirlenmiştir. Medial ve lateral menisküs yırtıklarında ayrım yapılmaksızın Mc murray testinin duyarlıığı \%68,9 eklem çızgısı hassasiyetinin duyarlılığı \%97,8 Mr görüntüleme yönteminin duyarlılığı \%93,3 olarak belirlenmiştir.

Sonuç: Dikkatli yapılan bir fizik muayenenin menisküs patolojilerini belirlemede en etkin tanı yöntemi olduğunu düşündürmektedir ve gereksiz yere MR tetkiki istemi oranlarını azaltabileceğini düşünmekteyiz.
\end{abstract}

Anahtar kelimeler: Artroskopi, menisküs, fizik muayene, MR

\section{ABSTRACT:}

Comparison of magnetic resonance imaging and pysical examination of knee with arthroscopic findings

Objective: To determine the effects of physical examination findings with the results of manyetik rezonans imaging (MRI) on the decision for arthroscopic surgery.

Methods: Preoperative physical examination findings and MRI results of the patients undergoing knee arthroscopy in our clinic were evaluated statistically by reference of arthroscopy retrospectively.

Results: The mean age of patients in the study is 47.2 (22.73), respectively. 25 of the patients were female, 20 of them were male. Arthroscopic surgery was performed for 27 left knee and 18 right knee. Mc Murray test sensitivity in patients with medial meniscus tear is $69.8 \%$. The medial joint line tenderness sensitivity is $97.7 \%$ in the patients with medial meniscus tear. Sensitivity of MRI is determined as $93 \%$ in the group with medial meniscus tear. Mc Murray test sensitivity in patients with lateral meniscal tear is $71.4 \%$. The lateral joint line tenderness sensitivity is $100 \%$ in the patients with lateral meniscus tear. Sensitivity of MRI is determined as $85.7 \%$ in the group with lateral meniscus tear. Mc Murray test sensitivity is $68.9 \%$, joint line tenderness sensitivity is $97.8 \%$ and sensitivity of MRI is determined as $93.3 \%$ without discrimination on the medial and lateral meniscal tear.

Conclusion: A careful physical examination is the most effective diagnostic method to determine meniscal pathologies. We think that careful physical examination could reduce the rates of unnecessary MRI exams.

Key words: Arthroscopy, meniscus, physical examination, MRI

Ş.E.E.A.H. Tıp Bülteni 2013;47(3):104-108
'Op. Dr., Özel Medipol Üniversitesi, Tıp Fakültesi Ortopedi ve Travmatoloji AD, İstanbul-Türkiye

${ }^{2} O p$. Dr., Or Ahayim Özel Balat Hastanesi, İstanbul-Türkiye

${ }^{3}$ Op. Dr., Özel Medipol Üniversitesi, Tıp Fakültesi Ortopedi ve Travmatoloji AD, İstanbul-Türkiye

Yazışma Adresi / Address reprint requests to: Op. Dr. Özgür Korkmaz, Or Ahayim Özel Balat Hastanesi, İstanbul-Türkiye

E-posta / E-mail: ozkorkmaz00@yahoo.com

Geliş tarihi / Date of receipt: 13 Ekim 2012 / October 13, 2012

Kabul tarihi / Date of acceptance: 31 Ekim 2012 / October 31, 2012 


\section{GiRiş VE AMAÇ}

Menisküs yırtıkları genç ve yaşlı hastalarda görülmektedir. Diz ağrısına, takılma ve kilitlenmeye neden olmaktadırlar (1). Diz manyetik rezonans (MR) görüntülemesi menisküs ve çapraz bağ yaralanması şüphesi olan hastalarda yapılmalıdır. Direkt radiografi, direkt impaksiyona bağlı bir travma olmadan çok az bilgi vermektedir (2). Genel popülasyonda ve yaşın ilerlemesiyle tesadüfi olarak MR da menisküs bulgularında artış görülmektedir (3). Menisküs yırtığının tanısının uygun şekilde ortaya konması yapılacak uygun tedavi protokolü için önemlidir. Detaylı anamnez ve fizik muayene menisküs yırtıklarını diğer diz sorunlarından ayrılmasında yardımcı olmaktadır (4-6).

Diz artroskopisi ortopedik cerrahi girişimler içerisinde en çok yapılan cerrahi girişimdir. Menisküs lezyonları ön çapraz bağ lezyonları ve gonartrozun tedavisinde artroskopik cerrahi kullanılmaktadır. Diz patolojilerinde fizik muayene bulgularından sonra artroskopik cerrahi girişim için MR görüntüleme yöntemi sıklıkla kullanılmaktadır.

Çalışmamızın amacı kliniğimizde yapılan diz artroskopisi bulguları ile ameliyat öncesi yapılan fizik muayene ve MR görüntüleme yöntemi bulgularının karşılaştırılması. Fizik muayene bulguları ile birlikte MR görüntüleme sonuçlarının artroskopik cerrahi yapılması kararı üzerine olan etkilerini belirlemek.

\section{GEREÇ VE YÖNTEM}

\section{Hastalar}

Çalışmamızda 2009-2012 tarihleri arasında kliniğimizde diz artroskopisi yapılan 45 hastanın ameliyat öncesi muayene bulguları, çekilen MR'ları ile artroskopik cerrahi esnasındaki bulguları karşılaştırıldı. Romatoid artrit ve daha önceden diz cerrahisi geçiren hastalar çalışmaya dahil edilmedi. Çalışmaya katılan hastaların yaş ortalaması 47,2 (22-73) yıl olarak belirlendi. Çalışmadaki hastaların 25'i kadın, 20'si erkek, 27 sol dize, 18 sağ dize artroskopik cerrahi yapıldı. Cerrahi yapılan hastalarda Mc Murray testi veya eklem çizgisi hassasiyeti mevcuttu ve MR raporlarında menisküs yırtığı rapor edilmişti. Medial Mc Murray testi; Krurise eksternal rotasyon-abduksiyon verilirken diz fleksiyon- dan ekstansiyona getirilirken klik ve/veya keskin ağrı aranır. Lateral Mc Murray testi; Krurise internal rotasyon-adduksiyon verilirken diz fleksiyondan ekstansiyona getirilirken klik ve/veya keskin ağrı aranır.

\section{MR Protokolü}

Hastaların manyetik rezonanas görüntülemeleri merkezimizde yapılmıştır. Standart görüntüleme protokolü sagittal spinal eko sagittal T1 ağırlıklı görüntülerde TR 520 TE 12, sagittal PD Fatsat ağırlıklı görüntülerde TR 2860 TE 45, koroner T2 Fatsat ağırlıklı görüntülerde TR 3520 TE 73, aksiyel PD Fatsat görüntülerde TR 2560 TE 40 ve aksiyel T2 FSE görüntülerde TR 3580 TE $117^{\prime}$ dir.

\section{Artroskopi}

Artroskopik girişimler turnike altında yapıldı. Antero lateral portal ilk olarak açıldı. Sonra artroskopi kontrolünde antero medial portal açıldı. Supra patellar bölge, medial gutter lateral gutter medial ve lateral kompartmanlar incelendi. 40 hastada medial menisküs yırtığı tespit edildi ve yırtıkların tiplendirmesi yapıldı (Şekil 1a-b). Parsiyel menisektomiler yapıldı (Şekil 2a-b). 7 hastada lateral menisküs yırtığı tespit edildi ve yırtıkların tiplemeleri yapıldı sonrasında parsiyel menisektomi yapıldı. Yapılan artroskopik cerrahi girişimlerde 3 ön çapraz bağ cerrahisi yapıldı ve yapılan ön çapraz bağ cerrahilerindede ameliyat öncesi MR görüntüleme yapılmıştır.

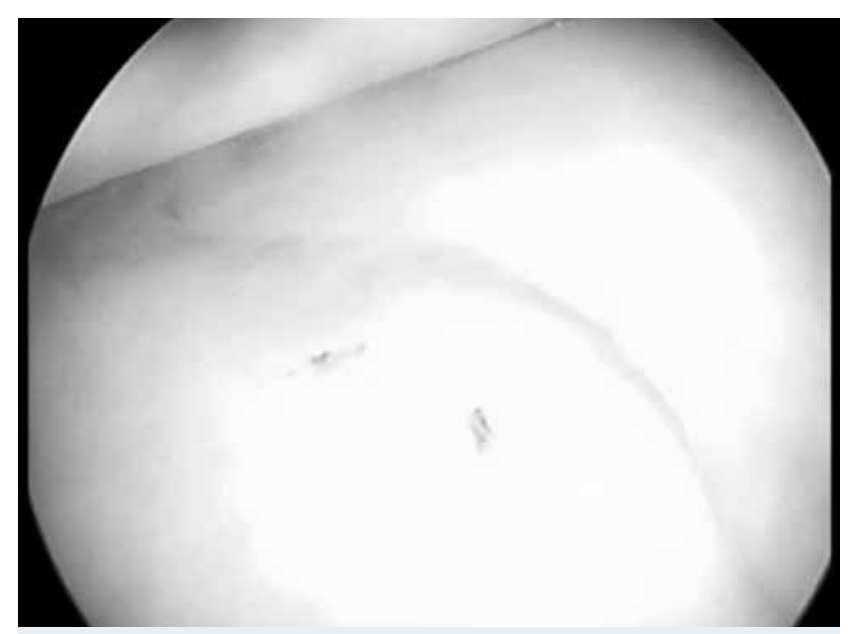

Şekil 1a: Medial menisküste dejeneratif kompleks yırtık 


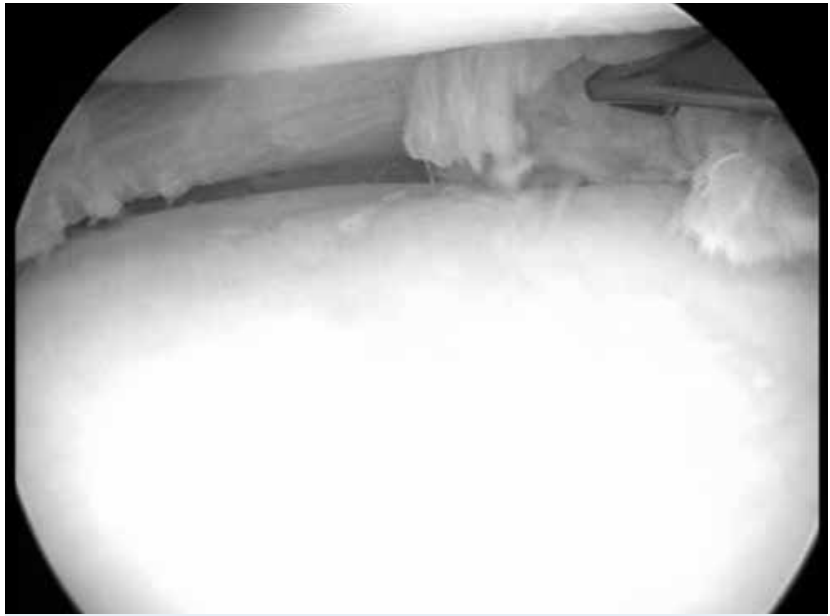

Şekil 1b: Medial menisküste dejeneratif kompleks yırtık

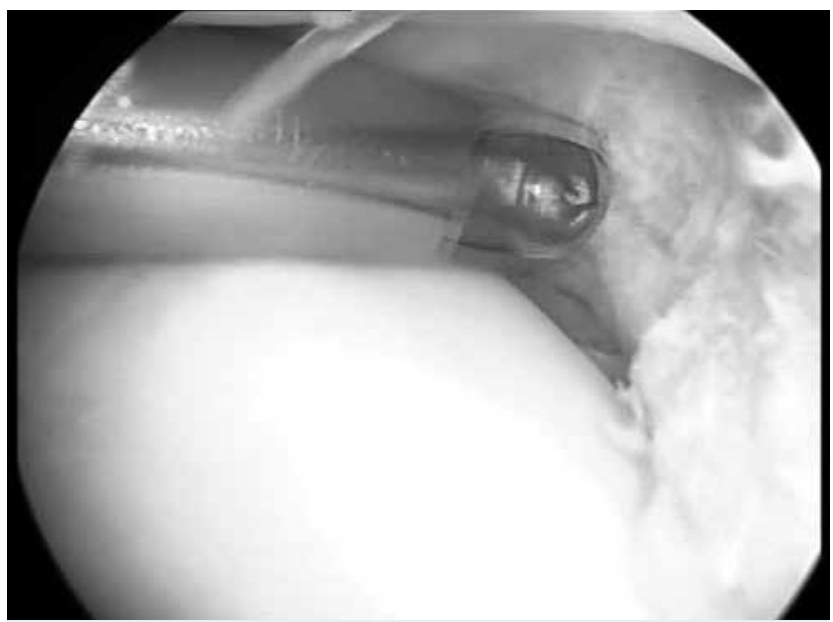

Şekil 2a: Parsiyel menisektomi

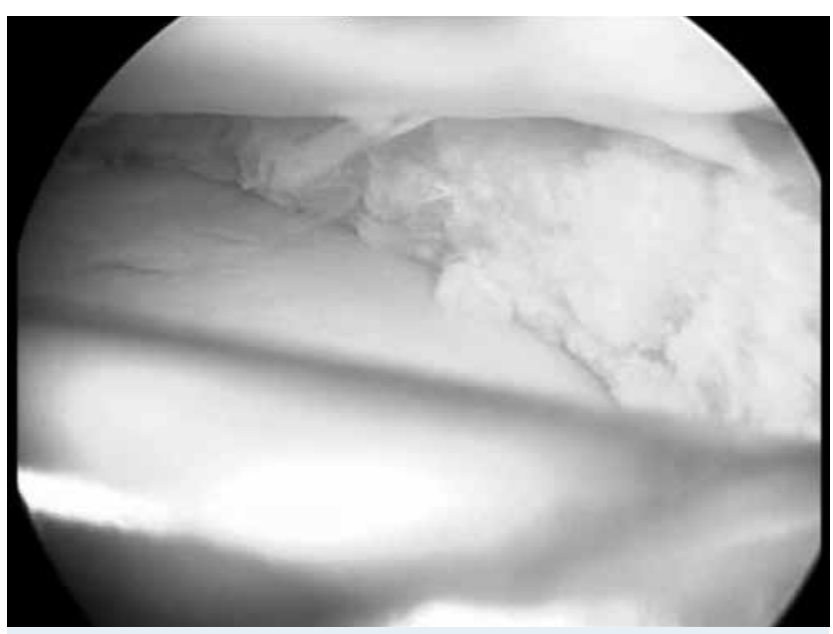

Şekil 2b: Parsiyel menisektomi

\section{İstatistiksel Analiz}

Referans tanı yöntemi olarak artroskopi alınarak MR, McMurray ve Eklem Çizgisi tanı yöntemlerinin duyarlılığı SPSS 16.0 programında dört gözlü tablo yöntemi ile hesaplandı.

\section{BULGULAR}

Medial menisküs yırtığı olan hastalarda Mc murray testinin duyarlılığı \%69,8 medial eklem çizgisi hassasiyetinin duyarlılığı \%97,7 MR görüntüleme yönteminin duyarlılı̆̆ı \%93 olarak belirlenmiştir (Tablo 1).

Tablo 1: Medial menisküs yırtığı olan hastalarda fizik muayene ve MR duyarlılıkları

\begin{tabular}{lc}
\hline Testler & \% Duyarlılık \\
\hline MR Medial & 93.0 \\
Mc Murray & 69.8 \\
Eklem Çizgisi & 97.7
\end{tabular}

Lateral menisküs yırtığı olan hastalarda Mc murray testinin duyarlılığı \%71,4 lateral eklem çizgisi hassasiyetinin duyarlılığı \%100 MR görüntüleme yönteminin duyarlılığı \%85,7 olarak belirlenmiştir (Tablo 2).

Tablo 2: Lateral menisküs yırtığı olan hastalarda fizik muayene ve MR duyarlılıkları

\begin{tabular}{lc}
\hline Testler & \% Duyarlılık \\
\hline MR Lateral & 85.7 \\
Mc Murray & 71.4 \\
Eklem Çizgisi & 100
\end{tabular}

Medial ve lateral menisküs yırtıklarında ayrım yapılmaksızın Mc murray testinin duyarlılığı \%68,9 eklem çizgisi hassasiyetinin duyarlılığı \%97,8 MR görüntüleme yönteminin duyarlılığı \%93,3 olarak belirlenmiştir (Tablo 3).

Tablo 3: Anatomik ayrım yapılmadan menisküs yırtığı olan hastalarda fizik muayene ve MR duyarlılıkları

\begin{tabular}{lc}
\hline Testler & \% Duyarlılık \\
\hline MR Medial ve/veya Lateral & 93.3 \\
Mc Murray & 68.9 \\
Eklem Çizgisi & 97.8
\end{tabular}




\section{TARTIŞMA}

Esperragoza ve ark yaptığı çalışmada MR'ın lateral menisküs yıtıklarını belirlemede duyarlılığını \%72 spesifikliğinin \%100, medial menisküs yırtıklarını belirlemede duyarlılığını \%85 spesifikliğinin \%89 olduğunu belirtmektedirler (7). Khanda ve ark yaptığı çalışmada MR'ın lateral menisküs yırtıklarını belirlemedeki sensitivitesi \%100 spesivitesi \%69,27 lateral menisküs yırtıklarını belirlemede sensitivitesi \%88,23 spesivitesi $\% 87,5$ olarak bildirmişlerdir (8). Çalışmamızın sonuçlarına göre MR görüntüleme yöntemi ile menisküs yırtıklarını belirlemede ki duyarlılıklar benzerdir.

Sampson ve ark 3T MR'ın medial menisküs yırtıklarını belirlemede sensivitesi \%91 spesivitesi \%93 lateral menisküs yırtıklarını belirlemede sensivitesi \%77 spesivitesi \%93 olduğunu belirlemişlerdir. Menisküs yırtığının tipi \%75 oranında, yırtığın lokalizasyonu \%94 oranında doğru olarak tespit edilmiştir (9). Von Hengelhardt ve ark yaptığı çalışmada 3 tesla $M R^{\prime} ı n$ medial menisküs yırtıklarını belirlemede sensitivitesi \%86, spesivitesi \%100 lateral menisküs yırtıkları için sensivitesi \%57, spesivitesi \%92 olarak belirlenmiştir. Kompleks ve horizontal tipte olan menisküs yırtıklarda performansın daha iyi olduğu radial yırtıklar için tanı değerinin azaldığı belirtilmektedir (10). Artroskopi yapılan hastalarda fizik muayene sonrası istenen MR görüntülemede $3 T^{\prime} l_{ı k}$ MR kullanılmamaıştır. Sonuçlarımla 3T MR ile yapılan görüntüleme sonuçları arasında anlamlı bir fark olmadığını düşünüyoruz ve $3 T$ ile yapılan MR görüntüleme tetkikinin zorunlu olmadığını düşünüyoruz.

Bouju ve ark yaptıkları çalışmada birinci değerlendirmede sensitiviteyi \%70 spesiviteyi \%81, ikinci değerlendirmede sensitiviteyi \%64 spesiviteyi \%90 olarak belirlemişler çalışma 69 çocuk dizinde MR sonrası yapılan artroskopiler sonucunda ortaya çıkmıştır (11). Çalışmamızda artroskopi yapılan pediatrik yaş gurubunda hasta olmaması çalışmayı kısıtlamaktadır.

Ercin ve ark. yaptığı çalışmanın sonucunda deneyimli bir cerrahın çeşitli menisküs testlerini kullanarak yaptığı klinik muayene menisküs yırtıklarının tanısı için yeterli olduğunu belirtmektedirler (12). Çalışmamızın sonuçlarına göre fizik muayene bulgularının menisküs yırtıklarını belirlemede çok etkili olduğunu düşünmekteyiz ve sonuçlarımız Ercin ve ark. yaptığı çalışma ile uyumludur.

Gökalp ve ark. yaptığı çalışmada ince kesit aksiyel MR görüntülerinin menisküs yırtıklarının tespitinde ve özellikle sınıflamasının yapılmasında sensivite ve spesiviteyi arttırdığını belirtmektedirler. Çalışmamızda ince kesit MR görüntüleme yapılmamasına rağmen artroskopi ve MR bulguları arasında yüksek sensivite olduğu tespit edilmiştir (13).

Ryzewicz ve ark. yaptığı çalışmada deneyimli bir klinisyenin yaptığı dikkatli bir muayene sonucunda cerrahi tedavi edilebilir menisküs lezyonu olan hastaları belirlemede MR görüntüleme yöntemine göre daha güvenilir olduğunu belirtmektedirler. Çalışmamızın sonuçlarına göre özellikle menisküs lezyonlarını belirlemede eklem çizgisi hassasiyetinin MR'a göre daha güvenilir olduğunu göstermektedir ve yapılan çalışma ile uyumludur (14).

Esmaili ve ark. yaptığı çalışma sonucunda medial menisküs yaralanmalarında fizik muayenenin \%96,9 MR'ın \%85,9, lateral menisküs yaralanmaları için fizik muayenenin \%85,4 MR'ın ise \%73,8 doğruluk oranları olduğunu bildirmekteler. Çalışmamızda iki fizik muayene yöntemi ve MR karşılaştırılmıştır. Çalışmamızda MR'ın menisküs lezyonlarını belirlemedeki oranı yapılan çalışmadakinden daha yüksektir ama fizik muayene yöntemlerinin menisküs lezyonlarını belirlemedeki oranları benzerdir (15).

Konan ve ark. yaptıkları çalışmada eklem çizgisi hassasiyetinin diğer muayene bulgularına göre tanı değerinin daha yüksek olduğunu belirtmekteler. Medial menisküs lezyonları için doğruluk oranını \%81 lateral menisküs lezyonları için \%90 olduğunu belirtmekteler (16). Eren'in yaptığı çalışma sonucunda eklem çizgisi hassasiyetinin lateral menisküs yırtıklarındaki doğruluk oranının \%96 sensivitesinin $89 \%$ ve spesivitesinin \%97 olduğunu medial menisküs yırtıkları için oranların daha düşük olduğunu bildirmiştir (17). Bu çalışmaların sonuçları ile çalışmamızın sonuçları benzerdir.

\section{SONUÇ}

Diz eklem içi lezyonlar çok sık görülmesine rağmen tam tanı yöntemleri tartışmalıdır (18). Çalışmamızın sonucuna göre dikkatli yapılan bir fizik muaye- 
nenin menisküs patolojilerini belirlemede en etkin tanı yöntemi olduğunu düşündürmektedir ve gerek- siz yere MR tetkiki istemi oranlarını azaltabileceğini düşünmekteyiz.

\section{KAYNAKLAR}

1. Terry GC, Tagert BE, Young MJ. Reliability of the clinical assessment in predicting the cause of internal derangements of the knee. Arthroscopy 1995;11(5):568-76.

2. McNally EG. Magnetic resonance imaging of the knee is accurate and helps in making therapeutic decisions. BMJ 2002;325:115-6.

3. Englund $M$, Guermazi $A$, Gale $D$, et al. Incidental meniscal findings on knee MRI in middle-aged and elderly persons. N Engl J Med 2008;359(11):1108-15.

4. Mohan BR, Gosal HS. Reliability of clinical diagnosis in meniscal tears. Int Orthop 2007;31(1):57-60.

5. Wagemakers HP, Heintjes EM, Boks SS, et al. Diagnostic value of history-taking and physical examination for assessing meniscal tears of the knee in general practice. Clin J Sport Med 2008;18(1):24-30.

6. Nickinson R, Darrah C, Donell S. Accuracy of clinical diagnosis in patients undergoing knee arthroscopy. Int Orthop 2010;34(1):3944.

7. Esparragoza-Montero R, Rodriguez-Diaz J, Lanier-Dominguez J, Molero-Campos M, Puccia-Scimonello M. Evaluation of meniscal morphology and relation between the diagnostic findings of magnetic resonance imaging and arthroscopy in lesions of the knee. Invest Clin 2009;50(1):35-44.

8. Khanda GE, Akhtar W, Ahsan H, Ahmad N. Assessment of menisci and ligamentous injuries of the knee on magnetic resonance imaging: correlation with arthroscopy. J Pak Med Assoc 2008;58(10):537-40.

9. Sampson MJ, Jackson MP, Moran CJ, Shine S, Moran R, Eustace SJ. Three Tesla MRI for the diagnosis of meniscal and anterior cruciate ligament pathology: a comparison to arthroscopic findings. Clin Radiol 2008;63(10):1106-11.
10. von Engelhardt $L V$, Schmitz A, Pennekamp PH, Schild HH, Wirtz $D C$, von Falkenhausen F. Diagnostics of degenerative meniscal tears at 3-Tesla MRI compared to arthroscopy as reference standard. Arch Orthop Trauma Surg 2008;128(5):451-6.

11. Bouju Y, Carpentier E, Bergerault F, De Courtivron B, Bonnard $C$, Garaud P. The concordance of MRI and arthroscopy in traumatic meniscal lesions in children. Orthop Traumatol Surg Res 2011;97(7):712-8.

12. Ercin E, Kaya I, Sungur I, Demirbas E, Ugras AA, Cetinus EM History, clinical findings, magnetic resonance imaging, and arthroscopic correlation in meniscal lesions. Knee Surg Sports Traumatol Arthrosc 2011;20(5):851-6.

13. Gökalp G, Nas OF, Demirag B, Yazici Z, Savci G. Contribution of thin slice $(1 \mathrm{~mm})$ axial proton density MR images for identification and classification of meniscal tears: correlative study with arthroscopy. Br J Radiol 2012;85(1018):e871-8.

14. Ryzewicz M, Peterson B, Siparsky PN, Bartz RL The diagnosis of meniscus tears: the role of MRI and clinical examination. Clin Orthop Relat Res 2007;455:123-33.

15. Esmaili Jah AA, Keyhani S, Zarei R, Moghaddam AK Accuracy of MRI in comparison with clinical and arthroscopic findings in ligamentous and meniscal injuries of the knee. Acta Orthop Belg 2005;71(2):189-96.

16. Konan S, Rayan F, Haddad FS Do physical diagnostic tests accurately detect meniscal tears? Knee Surg Traumatol ArthrosC 2009;17(7):806-11.

17. Eren OT. The accuracy of joint line tenderness by physical examination in the diagnosis of meniscal tears. Arthroscopy 2003;19(8):850-4.

18. Sanches Vas $C E$, de Camargo $O$, de Santana $P$ et al. Accuracy of magnetic resonance in identifying traumatic intraarticular knee lesions. Clinics (Sao Paulo) 2005;60(6):445-450. 